\title{
Recreational drug use and impulsivity in a population of Canadian undergraduate drinkers
}

\author{
Iris M. Balodis ${ }^{1+}$, Marc N. Potenza ${ }^{2,3}$ and Mary C. Olmstead ${ }^{1 *}$ \\ Department of Psychology, Queen's University, Kingston, ON, Canada \\ 2 Department of Psychiatry, Yale University School of Medicine, New Haven, CT, USA \\ ${ }^{3}$ Departments of Psychiatry and Child Study Center, Yale University School of Medicine, Connecticut Mental Health Center, New Haven, CT, USA
}

\section{Edited by:}

Jon E. Grant, University of Minnesota,

USA

\section{Reviewed by:}

Jon E. Grant, University of Minnesota, USA

Martin Zack, Centre for Addiction and Mental Health, Canada

*Correspondence:

Mary C. Olmstead, Department of Psychology, Queen's University, Kingston, ON, Canada K7L 3N6. e-mail: olmstead@queensu.ca

\section{${ }^{+}$Current address:}

Iris M. Balodis, Department of Psychiatry, Yale University School of Medicine, New Haven, CT, USA
The consumption of drugs during young adulthood may be particularly detrimental given important neurodevelopmental changes occurring during this period. As impulsivity may lead to substance use and substance use to the commission of seemingly impulsive acts, an improved understanding of the relationship between alcohol use, other substance use and impulsivity in young adults is important. We gathered information on self-reported impulsivity, recreational drug use, and drinking habits of 205 (105 female) undergraduate students. Results showed that $64 \%$ of the students reported using marijuana at least once and these individuals were more likely to report binge drinking. Polysubstance use, defined as using marijuana and at least one other illicit substance, was reported by $20 \%$ of students. These individuals reported more drinking occasions per month and had higher levels of trait impulsivity. Rates of recreational drug use were similar to those reported in recent national surveys, suggesting an increase in experimentation with specific illicit drugs. Given that a majority of undergraduate drinkers reported marijuana use and its association with binge drinking, future research should clarify the relationship between marijuana use and binge consumption of alcohol and prevention efforts should consider the conjoint targeting of marijuana and binge drinking. The associations between polysubstance use, binge-level alcohol consumption and elevated self-reported impulsivity suggests that perceived trait impulsivity across multiple domains may predispose to excessive use of multiple substances. Longitudinal studies should examine the contribution of impulsivity to the initiation and experimentation with illicit drugs and the influence of specific substances on impulsivity.

Keywords: college students, binge, ethanol, marijuana, illicit drugs, polysubstance use

\section{INTRODUCTION}

Rates of illicit substance use in college students remain high, with more than half of undergraduates reporting having used a drug recreationally in the past year (Johnston et al., 2007). Despite various prevention efforts, the reported rate of illicit drug use, other than marijuana, has remained relatively constant over the past 10 years in college populations at around 18\% (Johnston et al., 2007). Illicit drug users engage in greater risk-taking behaviors, including binge drinking, unprotected sex, and anti-social conduct, and are more likely to display other psychiatric conditions such as depression or attention deficit/hyperactivity disorder (Bruner and Fishman, 1998; Feigelman et al., 1998; Deas and Brown, 2006). These findings highlight the need for an improved understanding of factors underlying illicit drug use in college students.

Individual differences in personality or temperament may contribute to substance use and abuse. For example, impulsivity has been implicated in initial drug experimentation and use and continued drug use and relapse following abstinence (Everitt et al., 2008). Impulsivity is a construct that encompasses aspects of reward sensitivity, lapses of attention and intolerance of delays, and it has been described as a maladaptive tendency to react quickly and spontaneously with a reduced sensitivity to the negative consequences associated with the act (Evenden, 1999; Moeller et al., 2001a; Potenza, 2007; de Wit, 2009). Impulsivity may promote drug use through two separate, non-mutually exclusive processes. Initially, trait impulsivity may predispose an individual to sample and use recreational drugs: self-report, behavioral and physiological measures of disinhibition in children and young adults are associated with subsequent drug use (Iacono and McGue, 2006; Kirisci et al., 2007). Later, however, drug use may lead to further impairments in self-control that are manifested as disinhibited intake. In support of this idea, early developmental exposure to alcohol has been associated with the development of impulsivity in rats (Nasrallah et al., 2009). These mechanisms may explain the elevated impulsivity observed in substance dependent populations and its relationship to addiction severity, comorbidity with other addictive disorders, and treatment retention (Sher and Trull, 1994; Moeller et al., 2001b, 2002; Petry, 2001).

Undergraduate students provide a unique opportunity to study the relationship between impulsivity and drug use as this age group has the highest rates of illicit drug and alcohol use, with college students drinking significantly more than their non-college-attending peers (SAMHSA, 2003; Slutske, 2005). Wechsler et al. (1994) described binge drinking as involving four or more drinks for women and five or more drinks for men. More recently studies have begun to examine the potential interaction 
between impulsivity and recreational drug use in this population prone to binge drinking (James and Taylor, 2007; MacKillop et al., 2007; Littlefield et al., 2009), but little cross-cultural information exists in populations with different drug regulations (e.g., legal drinking age). The current study examined this relationship by collecting information on trait impulsivity, recreational drug use, and drinking habits of undergraduate students at a Canadian university. Data were collected through questionnaires administered while students were participating in laboratory experiments examining impulsivity and decision-making (Balodis et al., 2006, $2007,2009)$. We have previously reported a relationship between self-reported impulsivity scores with drinking behaviors and drinking expectations between genders in this undergraduate population (Balodis et al., 2009). We did not, however, detect a relationship between self-reported impulsivity and neurocognitive tasks, including an implicit conditioning task (Balodis et al., 2007) a decision-making task (the Iowa Gambling Task) or a behavioral impulsivity task (the Newman Perseveration Task) (Balodis et al., 2006). These prior studies, however, did not investigate the potential influence of recreational drug use. Given high rates of illicit drug use reported in college samples, we hypothesized that more than half of all students surveyed would report illicit drug use, particularly marijuana. We further hypothesized that the amount of recreational drug use would be associated with greater self-reported impulsivity. Finally, we also hypothesized that self-reported levels of impulsivity would relate to more severe patterns of alcohol use (binge and quantity/ frequency of drinking).

\section{MATERIALS AND METHODS \\ PARTICIPANTS}

Data were collected from 205 students at Queen's University in Kingston, ON, Canada between 2002 and 2007. Participants were recruited through classes and a student volunteer subject pool. Eligibility criteria included that participants consumed alcohol at least once per month. Approximately $15 \%$ of all participants sampled did not meet this criterion. Participants were 100 male and 105 female undergraduate students ranging in age from 19 to 27 years, with a mean age of $19.87(\mathrm{SD}=1.27)$. Data collection was approved by the Queen's University General Research Ethics Board.

\section{MEASURES}

\section{The Barratt Impulsiveness Scale}

The Barratt Impulsiveness Scale (BIS), version 11, was used as a self-report measure of impulsiveness. The BIS is a 30-item questionnaire with Non-planning, Motor, and Cognitive Impulsiveness subscales. Participants rate themselves on statements using a 4-point scale: rarely/never, occasionally, often or almost always. Items on the BIS are moderately correlated with each other and the scale shows a high test-retest reliability and a Cronbach's alpha coefficient of 0.83 for the total BIS score and between 0.59 and 0.74 for the subscales (Patton et al., 1995; Fossati et al., 2001; Stanford et al., 2009). Participants' ratings on the BIS were summed according to methods described by Patton et al. (1995), generating a total BIS score and scores for Motor, Non-planning, and Cognitive impulsivity subscales. Correlational analyses were performed using Pearson correlations.

\section{Personal drinking habits}

This self-report questionnaire contains questions regarding an individual's drinking habits, including the frequency, amount, and length of drinking occasions and accords with the brief assessment methods put forth for the study of epidemiological research in alcohol (Dawson and Room, 2000; Balodis et al., 2006, 2007, 2009). However, the formal psychometric properties of the instrument have not been assessed. Six individuals did not complete the personal drinking habits (PDH). Therefore, the results on this questionnaire are based on 199 participants in the current sample who completed this measure.

\section{Drug Use Questionnaire}

This self-report questionnaire contains questions regarding an individual's drug use history as well as the type of drug and frequency of drug use (Balodis et al., 2007). Questions on the Drug Use Questionnaire (DUQ) include "Have you ever used recreational drugs, other than alcohol?," "Do you use recreational drugs on a regular basis?", and "How often do you use each drug (e.g., daily, weekly, monthly)?” Answers from questions on the DUQ were dichotomously scored as yes/no for recreational drug use and, based on this information, individuals were divided into positive or negative groups (i.e., recreational/no recreational drug use).

\section{RESULTS}

\section{RECREATIONAL DRUG USE CHARACTERISTICS FROM THE DRUG USE OUESTIONNAIRE}

On the DUQ, $65.9 \%$ ( $n=135)$ of participants reported having used recreational drugs, other than alcohol, and of these individuals, all but one reported using marijuana (this participant reported using two pharmaceutical opiates). A one-sample chi-square test showed no significant gender differences in reporting recreational drug use $\left[\chi^{2}(1, n=204)=0.09, p>0.05\right]$.

Types of drugs listed by participants who reported drug use are presented in Figure 1.

Overall, $46.8 \%(n=96)$ reported having used only one drug (marijuana) and 19\% $(n=39)$ reported using multiple recreational drugs. Although there is heterogeneity in the use of the term "polysubstance," it will be used to refer to the use of two or more substances. Of those reporting polysubstance use, the mean number of drugs was $2.8(\mathrm{SD}=1.1)$. A one-sample chi-square test revealed that individuals who reported multiple drug use were more likely to use marijuana on a regular basis (i.e., weekly or monthly) than individuals who reported using only one drug or none $\left[\chi^{2}(2\right.$, $n=202)=48.10, p<0.001]$. Specifically, $57.9 \%$ of individuals who reported using marijuana on a regular basis were those who reported polysubstance use. In the whole sample, $20 \%(n=41)$ reported using drugs on a regular basis, with all of these individuals reporting marijuana use. Of those who mentioned regular marijuana use, $0.5 \%$ $(n=1)$ reported daily use, $34 \%(n=14)$ reported weekly use, $41 \%$ $(n=17)$ reported monthly use, and $22 \%(n=9)$ reported yearly use. There were no significant gender differences in reports of regular recreational drug use $\left[\chi^{2}(1, n=203)=0.13, p>0.05\right]$.

\section{BARRATT IMPULSIVENESS SCALE}

The overall mean score on the BIS was 64.14 ( SD = 10.3; $n=205)$. Multiple one-way ANOVAs examining BIS scores and recreational drug use (none, only marijuana, polysubstance) showed differences 


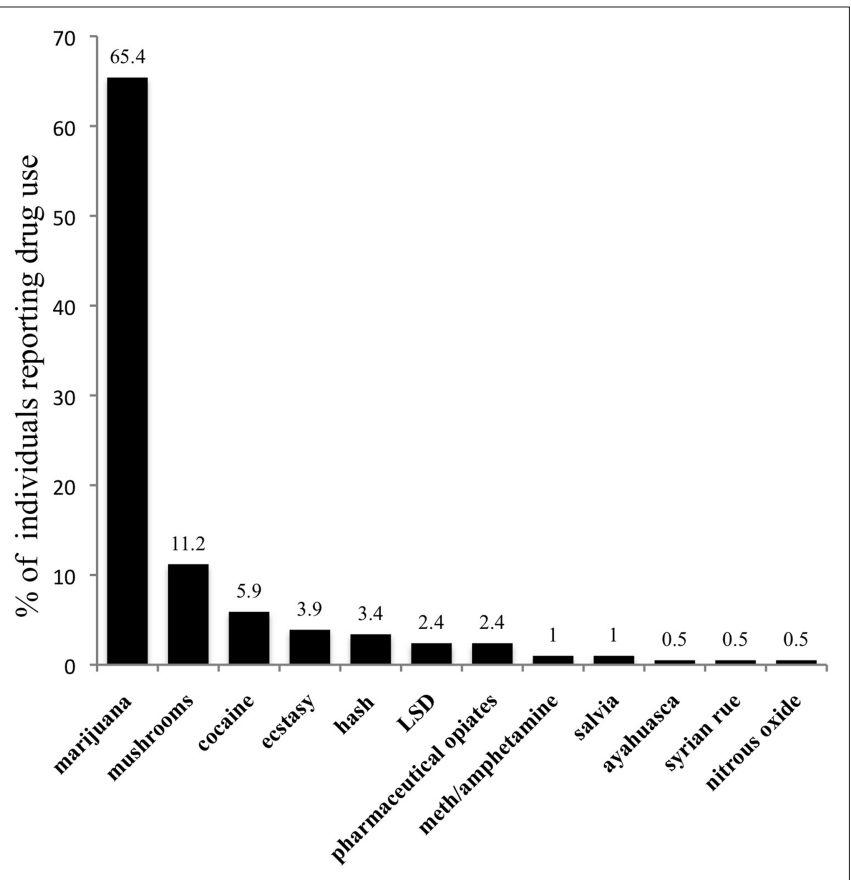

FIGURE 1 | Recreational drug use reported by 204 undergraduate students on the DUQ.

between groups on the total BIS score $[F(2,202)=5.35, p<0.01]$, as well as on the Non-planning subscale $[F(2,202)=4.04, p<0.05]$, Motor $[F(2,202)=3.50, p<0.05]$, and the Cognitive subscales $[F(2,202)=3.04, p=0.05]$. Polysubstance users scored higher on the BIS $(M=68.34, \mathrm{SD}=9.24)$ than did individuals who reported no recreational drug use $(M=61.73, \mathrm{SD}=10.03 ; p<0.05)$, but did not differ significantly from individuals who only reported marijuana use $(M=64.14, \mathrm{SD}=10.56 ; p=0.09)$. Similarly, on the Non-planning, Motor, and Cognitive subscales of the BIS, multiple one-way ANOVAs demonstrated that polysubstance users had significantly higher scores than individuals who reported no recreational drug use $(p<0.05)$, but not from individuals who reported only marijuana use (Figure 2 ). To control for the potential shared variance of binge drinking with recreational drug use, multiple one-way ANOVAs examining BIS scores and recreational drug use were also computed including when using binge drinking status as a covariate. The significant difference between recreational drug use groups still remained significant on the total BIS score $[F(2,195)=4.21, p=0.016]$, as well as for the Non-planning subscale $[F(2,195)=3.25, p<0.05]$, but not for the Cognitive $[F(2$, $195)=2.44, p=0.09]$ or for the Motor $[F(2,195)=2.56, p=0.08]$ subscales. Data on gender analyses with the BIS are published elsewhere (Balodis et al., 2009).

A Spearman correlation analysis showed a positive relationship between the number of drugs reported by participants and BIS scores. Specifically, the number of recreational drugs used was associated with higher scores on the BIS total score $(R=0.22$; $p<0.01)$, as well as the Non-planning $(R=0.17 ; p<0.05)$, Motor $(R=0.18 ; p<0.01)$, and Cognitive $(R=0.16 ; p<0.05)$ subscale scores.

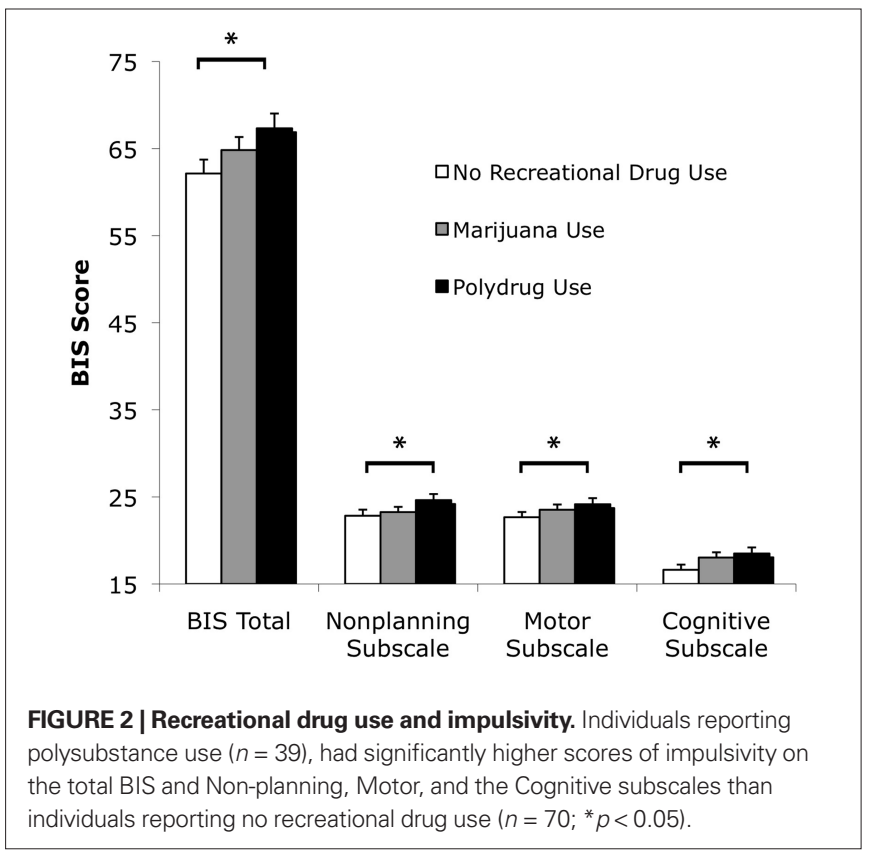

Multiple one-way ANOVAs examining BIS scores and regular drug use also showed differences between groups on the total BIS score $[F(1,202)=7.97, p<0.01]$ and the Non-planning subscale score $[F(1,202)=10.98, p<0.01]$, but not on the Motor $[F(1$, $202)=3.03, p=0.08]$ or Cognitive $[F(1,202)=2.93, p=0.09]$ subscale scores. Post hoc Bonferroni-corrected comparisons showed that on the BIS total, individuals who reported regular recreational drug use had significantly higher BIS total scores $(M=68.07$, $\mathrm{SD}=10.75)$ than did individuals who did not report regular drug use $(M=63.17, \mathrm{SD}=10.02 ; p<0.01)$. Regression analyses with categorical predictors yielded similar results.

\section{PERSONAL DRINKING HABITS}

Aone-sample chi-square test revealed that individuals who reported any drug use were more likely to be binge drinkers $\left[\chi^{2}(1, n=199)=5.10\right.$, $p<0.05]$. Multiple one-way ANOVAs showed a relationship between multiple recreational drug use and $\mathrm{PDH}$. Individuals who reported polysubstance use also reported significantly more drinking occasions per month than individuals who reported no recreational drug use $[F(2,195)=5.42, p<0.01 ; M=8.60, \mathrm{SD}=6.16$ vs. $M=5.80$, $\mathrm{SD}=3.58]$, but not a higher number of drinking occasions compared to those who reported just using marijuana $(p=0.10)$. There were no significant differences between recreational drug use groups and the number of drinks consumed on drinking occasions $[F(2,195)=1.06$, $p>0.05 ; M=6.13$ drinks, $\mathrm{SD}=2.79]$, nor on the length of a drinking occasion $[F(2,195)=0.97, p>0.05 ; M=4.61 \mathrm{~h}, \mathrm{SD}=1.31]$ (Figure 3). In order to control for the potential overlap between regular marijuana use and recreational drug use, multiple one-way ANOVAs examined the relationship between multiple recreational drug use and $\mathrm{PDH}$, with regular marijuana use entered as a covariate. With this variable added, the relationship with increased drinking occasions per month was no longer significant $(p=0.06)$, and there was still no relationship between the number of drinks consumed $(p=0.27)$, or with the length of the drinking occasions $(p=0.50)$. 


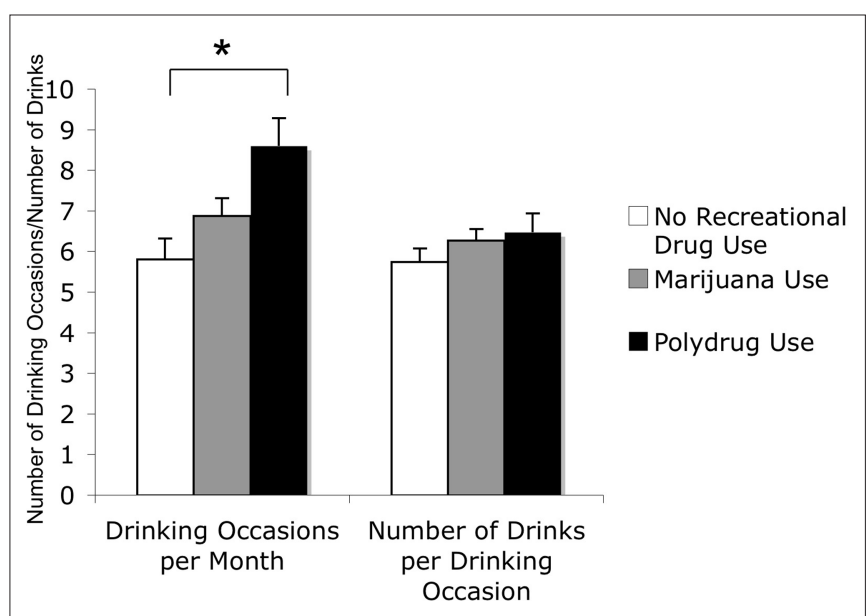

FIGURE 3 | Recreational drug use and personal drinking habits ( $n=198$ ). Individuals reporting polysubstance use $(n=38)$, reported significantly more drinking occasions per month than did individuals reporting no recreational drug use $\left(n=67 ;{ }^{*} p<0.05\right)$. There was no significant difference between drug use groups and the number of drinks consumed per drinking occasion.

Multiple one-way ANOVAs examining regular drug use and $\mathrm{PDH}$ showed a significant main effect of drinking occasions per month $[F(1,193)=5.58, p<0.05]$, whereby regular drug users reported significantly more drinking occasions per month $(M=8.13, \mathrm{SD}=4.70)$ than those who do not use drugs on a regular basis $(M=6.42, \mathrm{SD}=4.07)$. There were no significant difference between groups in the number of drinks consumed $[F(1$, $193)=0.05, p>0.05]$ or the duration of the drinking occasion $[F(1$, $193)=0.16, p>0.05]$. Separately including the total BIS score, or the three subscales, as covariates into the analyses did not alter the significance of the findings. Data on gender analyses with the $\mathrm{PDH}$ are published elsewhere (Balodis et al., 2009).

\section{DISCUSSION}

Consistent with our hypothesis, the current study found a relationship between impulsivity and the number of recreational drugs an individual reported using: higher impulsivity scores were associated with illicit drug use. Regular drug use was further related to higher impulsivity scores. Also consistent with our hypothesis, drug use was related to hazardous drinking behavior, as recreational drug users more frequently reported drinking beyond binge-thresholds. Additionally, polysubstance users differed from one-drug users, not in the amount of alcohol that they consumed, but rather in the frequency of their drinking behavior. Moreover, the frequency of illicit drug use in the current sample of college students is high and consistent with those described over the past 10 years. Distinctive types of recreational drug use, however, may differ slightly from those reported in previous decades in other samples.

\section{REPORTED DRUG USE AND IMPULSIVITY}

In line with our hypothesis, we found a relationship between impulsivity and reported drug use. We divided individuals according to their reported illicit drug use [none, one (typically marijuana) or multiple] and found increasing impulsivity scores in these groups. Examination of the BIS subscales showed that the Non-planning,
Motor, and Cognitive subscales all contributed to this effect. When controlling for the potential overlap between drug use and binge drinking status, the relationship between the BIS, as well as the Non-planning subscale still remained, suggesting that impulsivity may be related to recreational drug use even when accounting for the influence of binge drinking.

Given the multi-faceted construct of impulsivity (Evenden, 1999) and differences between self-reported and behavioral measures of impulsivity even within specific domains (Krishnan-Sarin et al., 2007), further investigations into the specific components at the subjective and behavioral levels are warranted. Future studies should longitudinally examine how impulsivity might change over time and which components of impulsivity contribute substantially to drug use; for example, whether aspects of risk-taking, disinhibition or the failure to evaluate negative consequences contribute most to self-reported impulsivity as it relates to drug use among undergraduate drinkers. These different domains of impulsivity may individually represent important markers of behavioral reactivity predicting vulnerability to future substance use and abuse (Littlefield et al., 2010). In addition to the relationship between polysubstance use and impulsivity, our study shows that individuals who reported more frequent or regular drug use also score higher on self-reported impulsivity and are more likely to be polysubstance users. These results may represent a distinction between noveltyseeking and impulsivity; whereas the majority of our participants $(65.9 \%)$ reported having tried marijuana, only approximately a fifth of the total sample reported taking recreational drugs on a regular basis (i.e., weekly or monthly). This is consistent with animal models demonstrating a dissociation between the trait of novelty-seeking, which predicts the propensity to initially administer a drug, and high levels of impulsivity, which predict the escalation of drug use, and is similarly observed in about $20 \%$ of rats (Belin et al., 2008). Therefore, in the current study, the high rates of impulsivity observed in the regular drug-using group may represent a vulnerable phenotype with the propensity to use drugs on a more habitual basis - an important stage in the development of addictive behavior.

\section{DRUG USE AND PERSONAL DRINKING HABITS}

The results from the PDH questionnaire also reinforce the idea that the frequency of substance use is an important differentiating factor when modeling drug use patterns. In a stepwise fashion, polysubstance users reported the highest number of drinking occasions per month (nine occasions), followed by those who only reported marijuana use (seven occasions/month) and then those who reported no drug use (six occasions). Although recreational drug users were more likely to be binge drinkers, drinking rates for the entire sample were very high. All groups (no drug users, recreational drug users and polysubstance users) reported drinking beyond binge-levels (means of 5.7, 6.3, and 6.5 drinks per drinking occasion, respectively). Binge drinking in college may be particularly hazardous as motivational neurocircuitry continues to develop during this epoch and ethanol consumption may damage frontal brain areas important for impulse control (Crews et al., 2000; Chambers et al., 2003; Monti et al., 2005). Moreover, repeated alcohol withdrawal is associated with greater harm when the dose and duration of alcohol exposure are controlled for, suggesting that 
repeated withdrawal may play a key role in damaging corticolimbic areas involved in executive functions and self-regulation (Duka et al., 2004). Therefore, the greater number of drinking occasions in the recreational drug-using group further may put this group at risk for withdrawal-related impairments in cognitive and emotional processing.

\section{REPORTED TYPES AND RATES OF DRUG USE}

The frequency of illicit drug use in this undergraduate population (i.e., 65.9\% reporting marijuana use) is consistent with rates reported in larger Canadian and American studies. For example, the Canadian Addiction Survey found that, in 20- to 24-year-olds, an overall percentage of lifetime use of any of six illicit drugs (cannabis, cocaine, speed, ecstasy, hallucinogens, and heroin) was 69.3\% (Adlaf et al., 2005). While the overall frequency of reported recreational drug use is similar, differences occur in the types of drugs reported across samples: our undergraduate sample reported greater marijuana use, but less use of other illicit drugs than in the general 20-24 age cohort of the Canadian Addiction Survey. These findings are consistent with those from larger American college studies demonstrating that, for most categories of illicit drugs, college students report lower rates of illicit drug use than their non-college attending peers (O'Malley and Johnston, 2002; Johnston et al., 2007). Also consistent with larger studies, we found that most individuals who reported marijuana use reported greater substance use in general, including alcohol (Mohler-Kuo et al., 2003). Indeed, recreational drug users were more likely to be binge drinkers. It should be noted that in comparison to these other studies, the current study focused on undergraduate alcohol drinkers and thus might not be directly comparable. Regardless, the observed pattern of polysubstance use has implications for prevention programs, particularly those on college campuses, and suggests that such programs may need to target substances and behaviors more broadly.

The current sample also distinguished types of recreational drug use from previous generations of college-aged individuals. More specifically, we noted comparably less use of hallucinogens and designer drugs and more use of narcotics other than heroin. In our study, frequencies of LSD, ecstasy and cocaine use appear similar to those in a 2007 study in the United States $(5.4,2.2$, and $1.3 \%$ respectively), which, in turn, appear to have decreased from 2000 (Johnston et al., 2007). In addition, reported use of salvia and pharmaceutical opiates are consistent with rates reported in larger American studies and, albeit low, support the idea that the collective abuse of non-medical prescription pain relievers may be increasing in the college population (McCabe et al., 2005; Lange et al., 2008). These results also support the finding that most non-medical prescription drug users in college are polysubstance users (McCabe and Teter, 2007).

\section{LIMITATIONS AND FUTURE DIRECTIONS}

The results of the current study are restricted by the small sample size and the limitations associated with self-report measures. While we found statistically significant differences between recreational drug use groups and impulsivity, it should be noted that the effect sizes, overall, were small to modest. For example, the partial eta squared for the relationship between BIS and recreational drug use was only 0.05 , suggesting that recreational drug use status accounted for approximately $5 \%$ of the total variability in BIS scores. While the binge drinking threshold is based on research demonstrating that drinking at this level is associated with a greater likelihood of experiencing alcohol-related problem (Wechsler et al., 1994), the current study did not specifically question participants about harm related to their drinking habits.

Although the drug types and rates reported by the DUQ are consistent with those reported in larger Canadian and American studies, future research should examine its psychometric properties and relationship to widely used, validated measures, such as the Drug Abuse Screening Test (DAST), that examine type and pattern of drug use. Our data are also derived from undergraduate students who report consuming alcohol at least once per month. Based on this criterion, approximately $15 \%$ of the students screened were not eligible for participation in the studies.

Extensive longitudinal research is important for more closely characterizing the relationship between impulsivity and substance use, specifically in the contribution of this construct to the initiation of drug use, as well as in how long term changes in impulsivity might relate to declines in substance misuse. For example, impulsivity and theoretically related constructs like sensation seeking and risk taking relate to developmental changes associated with problematic alcohol use (Littlefield et al., 2010; MacPherson et al., 2010). Therefore, it is important to consider the relationships over time between drug use and factors like impulsivity.

In the current study, while the majority of students reported having tried marijuana, trait impulsivity was highest in polysubstance and regular drug-using groups. In the future, it will also be important to better determine how different aspects of impulsivity relate to specific problems experienced with alcohol and drug misuse, as the current study did not examine the extent of negative consequences associated with different patterns of use. Longitudinal studies may determine whether the higher impulsivity scores predate the drug use and contribute to the drug use pattern. Some preliminary evidence suggests that high measures of impulsivity may predict increased alcohol and cigarette use (Grano et al., 2004); however, few studies have longitudinally followed a college sample, a population at seemingly high risk for illicit drug use and abuse.

\section{CONCLUSIONS}

In the current study, impulsivity was related to the reported level of illicit drug use and was further associated with regular drug use. Recreational drug users were also more likely to report drinking alcohol at binge-levels, and polysubstance users reported more frequent drinking occasions. Although the current study consisted of a relatively small sample, frequencies and types of illicit drug use were largely similar to those reported in large American and Canadian national surveys of similarly aged individuals.

These results have significant implications for understanding risk behaviors in specific populations. Undergraduate students experience a distinctive social environment that often facilitates drug and alcohol use; concurrently, these individuals are at a developmental stage where disturbances in neural maturation could alter processes involved in self-regulation. Antecedent characteristics, through family history or other variables, could further interact to increase the susceptibility to use and abuse of drugs. Additionally, differences in the perceived effects of intoxication exist for heavy substance 
users and may be related to alterations in reward-related learning processes that act as important markers for addiction vulnerability (Balodis et al., 2009). Further longitudinal research into the relationship between impulsivity and both licit and illicit drug use is necessary, specifically examining which components of impulsivity may relate to the reinforcing properties of these substances and to the experience of negative consequences. These findings may inform prevention strategies targeting specific individuals at risk for substance use and abuse, including undergraduate drinkers.

\section{ACKNOWLEDGMENTS}

This research was supported by the Ontario Problem Gambling Research Centre (OPGRC), National Sciences and Engineering Research Council of Canada (NSERC), NIAAA grant RL1 AA017539, NIDA grant RL5 DA024858, VA VISN1 MIRECC, REAP, UL1DE19586, and the NIH Roadmap for Medical Research/Common Fund. The authors would like to thank Dr. Ernest Barratt for the use of the BIS. The authors gratefully acknowledge Sheila DillonLeitch, Kirsten Johnson, Vivian Lee, and Hayley Walkden for their contributions in collecting the data.

\section{REFERENCES}

Adlaf,E. M., Begin, P., and Sawka,E. (2005). Canadian Addiction Survey (CAS): A National Survey of Canadians' Use of Alcohol and Other Drugs: Prevalence of Use and Related Harms: Detailed Report. Ottawa: Canadian Centre on Substance Abuse.

Balodis, I. M., Johnsrude, I. S., and Olmstead, M.C. (2007). Intact preference conditioning in acute intoxication despite deficient declarative knowledge and working memory. Alcohol. Clin. Exp. Res. 31, 1800-1810.

Balodis, I. M., MacDonald, T. K., and Olmstead, M.C. (2006). Instructional cues modify performance on the Iowa Gambling Task. Brain Cogn. 60, 109-117.

Balodis, I. M., Potenza, M. N., and Olmstead, M. C. (2009). Binge drinking in undergraduates: relationships with sex, drinking behaviors, impulsivity, and the perceived effects of alcohol. Behav. Pharmacol. 20, 518-526.

Belin, D., Mar,A.C., Dalley, J. W., Robbins, T. W., and Everitt, B. J. (2008). High impulsivity predicts the switch to compulsive cocaine-taking. Science 320, 1352-1355.

Bruner, A. B., and Fishman, M. (1998). Adolescents and illicit drug use. JAMA 280, 597-598.

Chambers, R.A., Taylor, J. R., and Potenza, M. N. (2003). Developmental neurocircuitry of motivation in adolescence: a critical period of addiction vulnerability. Am. J. Psychiatry 160, 1041-1052.

Crews, F. T., Braun, C. J., Hoplight, B., Switzer, R. C. III, and Knapp, D. J. (2000). Binge ethanol consumption causes differential brain damage in young adolescent rats compared with adult rats. Alcohol. Clin. Exp. Res. 24, 1712-1723.

Dawson, D. A., and Room, R. (2000). Towards agreement on ways to measure and report drinking patterns and alcohol-related problems in adult general population surveys: the Skarpo conference overview. J. Subst. Abuse $12,1-21$. Adolescent substance abuse and psychiatric comorbidities. J. Clin. Psychiatry 67, e02.

de Wit, H. (2009). Impulsivity as a determinant and consequence of drug use: a review of underlying processes. Addict. Biol. 14, 22-31.

Duka, T., Gentry, J., Malcolm, R., Ripley, T. L., Borlikova, G., Stephens, D. N., Veatch,L.M., Becker, H.C., and Crews, F. T. (2004). Consequences of multiple withdrawals from alcohol. Alcohol. Clin. Exp. Res. 28, 233-246.

Evenden, J. L. (1999). Varieties of impulsivity. Psychopharmacology (Berl.) 146, 348-361.

Everitt, B. J., Belin, D., Economidou, D., Pelloux, Y., Dalley, J. W., and Robbins, T. W. (2008). Review. Neural mechanisms underlying the vulnerability to develop compulsive drug-seeking habits and addiction. Philos. Trans. R. Soc. Lond., B, Biol. Sci. 363, 3125-3135.

Feigelman, W., Wallisch, L. S., and Lesieur, H. R. (1998). Problem gamblers, problem substance users, and dual-problem individuals: an epidemiological study. Am. J. Public Health 88, 467-470.

Fossati, A., Di Ceglie, A., Acquarini, E., and Barratt, E.S. (2001). Psychometric properties of an Italian version of the Barratt Impulsiveness Scale-11
Deas, D., and Brown, E. S. (2006).

\section{DISCLOSURES}

Dr. Potenza has received financial support or compensation for the following: Dr. Potenza consults for and is an advisor to Boehringer Ingelheim; has consulted for and has financial interests in Somaxon; has received research support from the National Institutes of Health, Veteran's Administration, Mohegan Sun, Institute for Research on Problem Gambling and the National Center for Responsible Gaming, and Forest Laboratories, Ortho-McNeil, Oy-Control/Biotie and Glaxo-SmithKline pharmaceuticals; has participated in surveys, mailings or telephone consultations related to drug addiction, impulse control disorders or other health topics; has consulted for law offices and the federal public defender's office in issues related to impulse control disorders; has performed grant reviews for the National Institutes of Health and other agencies; has given academic lectures in grand rounds, CME events and other clinical or scientific venues; has generated books or book chapters for publishers of mental health texts; and provides clinical care in the Connecticut Department of Mental Health and Addiction Services Problem Gambling Services Program.

(BIS-11) in nonclinical subjects. J. Clin. Psychol. 57, 815-828.

Grano, N., Virtanen, M., Vahtera, J., Elovainio, M., and Kivimaki, M. (2004). Impulsivity as a predictor of smoking and alcohol consumption. Pers. Individ. Dif. 37, 1693-1700.

Iacono, W. G., and McGue, M. (2006) Association between P3 eventrelated brain potential amplitude and adolescent problem behavior. Psychophysiology 43, 465-469.

James, L. M., and Taylor, J. (2007). Impulsivity and negative emotionality associated with substance use problems and Cluster B personality in college students. Addict. Behav. 32, 714-727.

Johnston, L. D., O’Malley, P. M., Bachman, J. G., and Schulenberg, J. E. (2007). Monitoring the Future National Survey Results on Drug Use, 1975-2007, Vol. 1. Bethesda, MD: U.S. Department of Health and Human Services, National Institutes of Health.

Kirisci, L., Tarter, R., Mezzich, A., and Vanyukov, M. (2007). Developmental trajectory classes in substance use disorder etiology. Psychol. Addict. Behav. 21, 287-296.

Krishnan-Sarin, S., Reynolds, B., Duhig, A. M., Smith, A., Liss, T., McFetridge, A., Cavallo, D. A., Carroll, K. M., and Potenza, M. N. (2007). Behavioral impulsivity predicts treatment outcome in a smoking cessation program for adolescent smokers. Drug Alcohol Depend. 88, 79-82.

Lange, J. E., Reed, M. B., Croff, J. M., and Clapp, J. D. (2008). College student use of Salvia divinorum. Drug Alcohol Depend. 94, 263-266.

Littlefield, A. K., Sher, K. J., and Steinley, D. (2010). Developmental trajectories of impulsivity and their association with alcohol use and related outcomes during emerging and young adulthood I. Alcohol. Clin. Exp. Res. 34, 1409-1416. Littlefield, A. K., Sher, K. J., and Wood, P. K. (2009). Is "maturing out" of problematic alcohol involvement related to personality change? J. Abnorm. Psychol. 118, 360-374.

Littlefield, A. K., Sher, K. J., and Wood, P. K. (2010). Do changes in drinking motives mediate the relation between personality change and "maturing out" of problem drinking? J. Abnorm. Psychol. 119, 93-105.

MacKillop, J., Mattson, R. E., Anderson Mackillop, E. J., Castelda, B. A., and Donovick, P. J. (2007). Multidimensional assessment of impulsivity in undergraduate hazardous drinkers and controls. J. Stud. Alcohol Drugs 68, 785-788.

MacPherson, L., Magidson, J. F., Reynolds, E. K., Kahler, C. W., and Lejuez, C. W. (2010). Changes in sensation seeking and risk-taking propensity predict increases in alcohol use among early adolescents. Alcohol. Clin. Exp. Res. 34, 1400-1408.

McCabe, S.E., and Teter, C. J. (2007). Drug use related problems among nonmedical users of prescription stimulants: a web-based survey of college students from a Midwestern university. Drug Alcohol Depend. 91, 69-76.

McCabe, S. E., Teter, C. J., Boyd, C. J., Knight, J. R., and Wechsler, H. (2005). Nonmedical use of prescription opioids among U.S. college students: prevalence and correlates from a national survey. Addict. Behav. 30, 789-805.

Moeller, F. G., Barratt, E. S., Dougherty, D. M., Schmitz, J. M., and Swann, A. C. 
(2001a). Psychiatric aspects of impulsivity. Am. J. Psychiatry 158, 1783-1793.

Moeller, F. G., Dougherty, D. M., Barratt, E. S., Schmitz, J. M., Swann, A. C., and Grabowski, J. (2001b). The impact of impulsivity on cocaine use and retention in treatment. J. Subst. Abuse Treat. 21, 193-198.

Moeller, F. G., Dougherty, D. M., Barratt, E. S., Oderinde, V., Mathias, C. W., Harper, R. A., and Swann, A. C. (2002). Increased impulsivity in cocaine dependent subjects independent of antisocial personality disorder and aggression. Drug Alcohol Depend. 68, 105-111.

Mohler-Kuo, M., Lee, J. E., and Wechsler, H. (2003). Trends in marijuana and other illicit drug use among college students: results from 4 Harvard School of Public Health College Alcohol Study surveys: 1993-2001. J. Am. Coll. Health 52, 17-24.

Monti, P. M., Miranda, R. Jr., Nixon, K., Sher, K. J., Swartzwelder, H. S., Tapert, S. F., White, A., and Crews, F. T. (2005). Adolescence: booze, brains, and behavior. Alcohol. Clin. Exp. Res. 29, 207-220.

Nasrallah, N. A., Yang, T. W., and Bernstein, I. L. (2009). Long-term risk preference and suboptimal decision making following adolescent alcohol use. Proc. Natl. Acad. Sci. U.S.A. 106, 17600-17604.

O'Malley, P. M., and Johnston, L. D. (2002). Epidemiology of alcohol and other drug use among American college students. J. Stud. Alcohol Suppl. 14, 23-39.

Patton, J. H., Stanford, M. S., and Barratt, E. S. (1995). Factor structure of the Barratt Impulsiveness Scale. J. Clin. Psychol. 51, 768-774.

Petry, N. M. (2001). Pathological gamblers, with and without substance use disorders, discount delayed rewards at high rates. J. Abnorm. Psychol. 110, 482-487.

Potenza, M. N. (2007). To do or not to do? The complexities of addiction, motivation, self-control, and impulsivity. Am. J. Psychiatry 164, 4-6.
SAMHSA. (2003). Results from the 2002 National Survey on Drug Use and Health: National Findings. NHSDA Series H-22, DHHS Publication No. SMA 03-3836. Rockville, MD: Office of Applied Studies.

Sher, K. J., and Trull, T. J. (1994). Personality and disinhibitory psychopathology: alcoholism and antisocial personality disorder. J. Abnorm. Psychol. 103, 92-102.

Slutske, W. S. (2005). Alcohol use disorders among US college students and their non-college-attending peers. Arch. Gen. Psychiatry 62, 321-327.

Stanford, M.S., Mathias, C.W., Dougherty, D. M., Lake, S. L., Anderson, N. E. and Patton, J. H. (2009). Fifty years of the Barratt Impulsiveness Scale: an update and review. Pers. Individ. Dif. 47, 385-395.

Wechsler, H., Davenport, A., Dowdall, G. Moeykens, B., and Castillo, S. (1994). Health and behavioral consequences of binge drinking in college. A national survey of students at 140 campuses. JAMA 272, 1672-1677.
Conflict of Interest Statement: The authors declare that the research was conducted in the absence of any commercial or financial relationships that could be construed as a potential conflict of interest.

Received: 12 March 2010; paper pending published: 20 July 2010; accepted: 11 August 2010; published online: 21 October 2010. Citation: Balodis IM, Potenza MN and Olmstead MC (2010) Recreational drug use and impulsivity in a population of Canadian undergraduate drinkers. Front. Psychiatry 1:129. doi: 10.3389/ fpsyt.2010.00129

This article was submitted to Frontiers in Impulsivity, Compulsivity and Behavioral Dyscontrol, a specialty of Frontiers in Psychiatry.

Copyright (C) 2010 Balodis, Potenza and Olmstead. This is an open-access article subject to an exclusive license agreement between the authors and the Frontiers Research Foundation, which permits unrestricted use, distribution, and reproduction in any medium, provided the original authors and source are credited. 